\title{
SEALING OF BONDED RESIN COMPOSITE TO GINGIVAL WALL FOLLOWING APPLICATION OF TWO HEMOSTATIC AGENTS USING TWO ADHESIVE PROTOCOLS: AN INVITRO STUDY
}

\author{
Hossam Al Mandouh* and Inas Alzayat**
}

\begin{abstract}
Aim: To evaluate the microleakage of self-etch adhesive used with and without pre-etching step, on human dentin contaminated with two different hemostatic agents.

Materials and methods Thirty human premolars were collected and class V cavities with standard dimensions were prepared at the cemento-enamel junction on both buccal and lingual surfaces, with the gingival margin is totally placed in dentin. All specimens were randomly assigned into three groups according to the hemostatic agent used (A); A0: No hemostatic agent applied (control group). A1: Hemostop (Dentsply). A2:ViscoStat ${ }^{\circledR}$ (Ultradent). Each group was furtherly subdivided into two subgroups according to the adhesive protocol used (B); B1: Pre-etching was performed. B2: Pre-etching was not performed. The resultant will be six subgroups, each of them was formed of five teeth with 10 cavities $(n=10)$. Filtek ${ }^{\mathrm{TM}} \mathrm{Z} 350$ XT nano resin was used to restore all cavities according to the manufacturer's instructions. Teeth were exposed to a thermocycling procedure, thereafter, they were stored in artificial saliva for two years. After immersion in $2 \%$ methylene blue dye, Microleakage was measured using USB Digital microscope with a built-in camera connected with an IBM compatible personal computer using a fixed magnification of $40 \mathrm{X}$.
\end{abstract}

Results: A two-way unrelated ANOVA showed significant main effects $(p=0.0001)$ for hemostatic agent, with large effect size $\eta^{2}=86.5 \%$, adhesive protocol with medium effect size $\eta^{2}=68.6 \%$, and the interaction between hemostatic agent and adhesive protocol but with small effect size $\eta^{2}=34.2 \%$. The Duncan post-hoc test revealed a significant difference between all groups except between the groups of Viscosat with pre-etching adhesive protocol $(0.54 \pm 0.03)$ on one hand and Hemostop with and without pre-etching adhesive protocol $(0.53 \pm 0.02)$ and $(0.61 \pm 0.04)$, respectively on the other hand $(\mathrm{p}>0.05)$.

Conclusions: 1 . Contamination with hemostatic agents adversely affected the bonding qualities of self etch adhesives applied with and without pre etching step. 2. Dentin etching prior to self etch adhesives minimized the harmful effect of the hemostatic agents.

* Lecturer, Operative Dentistry Department, Faculty of Dentistry, Suiz Canal University.

** Assistant Professor, Operative Dentistry Department, Faculty of Dentistry, Misr International University. 


\section{INTRODUCTION}

The past years have witnessed great advances in bonding techniques, technologies and applications in the dental field, resulting in a more durable and reliable bond between resin composites and tooth structures. Single-component, light-curing adhesives were introduced to shorten the clinical steps and simplify the bonding procedures.

To achieve a successful resin composite restoration, proper isolation is mandatory. Contamination will have an unfavorable effect on the longevity of the restoration, deterring its clinical performance and success. ${ }^{1}$ Contaminated cavities impair visualization and accessibility, resulting in microleakage, which in turn can give rise to tooth hypersensitivity, pulpal irritation, tooth discoloration, recurrent caries and eventually clinical failure. ${ }^{2}$ During most clinical procedures, rubber dam can aid as a physical barrier precluding external fluids and avoiding saliva and/or blood contamination. However, there are conditions in which the use of the rubber dam is a challenging and very hard procedure. It is then substituted by gingival retraction cords and hemostatic agents to control the flow of gingival fluid and the blood contamination on the prepared dentin. This could impair the bond strength during the restorative procedure. ${ }^{3}, 4$

Hemostatic agents are widely used as a method of easier bleeding and fluid control in dentistry. While some drawbacks have been investigated, it is predicted that accurate use of these materials can minimize their negative effects and exploit their advantages. Some adverse effects, such as inflammation and tissue necrosis, are already solved by lower concentrations and gel-type formulations marketed by manufacturers. ${ }^{5}$

Hemostatic agents have been offered in several formulations with different mechanisms of action, such as ferric sulfate compounds, aluminum chloride, iron solution, aluminum and potassium sulfate and $0.1 \%$ epinephrine. ${ }^{6}$

Hemostop (HS) and ViscoStat ${ }^{\circledR}$ (VS) are two hemostatic agents that are available in Egypt. They provide efficient isolation from sulcular fluid, blood and saliva. HS consists of a $25 \%$ aluminum chloride solution while VS of a $20 \%$ ferric sulfate solution. Hemostasis with these solutions is accomplished by coagulation plugs blocking capillary openings resulting in a very fast blood coagulation, that is why it must be placed directly against the cut tissue. ${ }^{7}$ The suggested application time is $1-3$ min. ${ }^{8}$

On the other hand, hemostatic agents are acidic $(\mathrm{pH}=0.7-3)$ and have hydrophilic characteristics thus could contaminate all the stages of bonding procedures. ${ }^{9}$ The application of the such hydrophilic hemostatic agents could alter the dentin surface morphology and can affect the bond strength of adhesive resins. ${ }^{10}$

Little is known about the effect of hemostatic agents on microleakage of resin composite restorations with different adhesive resins systems. This study was undertaken to evaluate the microleakage of one self etch adhesive with and without prior dentin etching, on human teeth contaminated with two different hemostatic agents. The null hypothesis tested was that these hemostatic agents do not affect marginal microleakage.

\section{MATERIAL AND METHODS}

A total of thirty non-carious human premolars, freshly extracted for orthodontic reasons stored in $0.2 \%$ thymol solution at $4^{\circ} \mathrm{C}$, were used in the present study. Twenty-four hours before the study procedures, all teeth were removed from the thymol solution and stored in distilled water at $37^{\circ} \mathrm{C}$ before being prepared. Prior to tooth preparation the dimensions of each cavity were drawn on the buccal and lingual surfaces of all teeth using a standard template. Class V cavities (2 $\mathrm{mm}$ in depth, $3 \mathrm{~mm}$ mesiodistally, $2 \mathrm{~mm}$ occluso-gingivally) 
were prepared at the cemento-enamel junction on both buccal and lingual surfaces, with the occlusal margin is located on enamel, meanwhile the gingival one is totally placed in dentin. The cavities were prepared using a straight fissure diamond bur (MANI Ltd., Utsunomiya, Japan) in a watercooled high-speed handpiece. The bur was replaced after every five preparations. During preparation tooth surfaces were kept wet all the times to avoid dehydration. The depth of the prepared cavities was measured by a periodontal probe. The gingival wall of the prepared cavities was contaminated with the assigned hemostatic gent then the whole cavity was restored following the manufacturer's instructions. Material used in the study with its composition are shown in table 1.

\section{Specimens grouping}

All specimens were randomly assigned into three groups according to the hemostatic agent used (A); A0: No hemostatic agent applied (control group). A1: Hemostop (Dentsply). A2:ViscoStat ${ }^{\circledR}$ (Ultradent). Each group was furtherly subdivided into two subgroups according to the adhesive protocol used (B); B1: Pre-etching was performed. B2: Pre-etching was not performed. The resultant will be six subgroups, each of them was formed of five teeth with 10 cavities $(n=10)$ and prepared as follow:

- Group 1 (A0B1): Cavity was restored without application of hemostatic agent. The tooth was air-dried to remove excess moisture. Then etching was done by the application of $34 \%$

TABLE (1) Materials used in the study

\begin{tabular}{|c|c|c|c|}
\hline Material & Commercial brand & Manufacturer & Composition \\
\hline Hemostatic agent 1 & Hemostop & $\begin{array}{l}\text { Dentsply Indústria e } \\
\text { Comércio Ltda, RJ, } \\
\text { Brazil }\end{array}$ & $\begin{array}{l}95 \% \text { ethyl alcohol, isopropyl alcohol, aluminum } \\
\text { chloride pa } \\
13 \% \text { to } 15 \% \text {, hydroxyquinoline sulfate, propylene } \\
\text { glycol }\end{array}$ \\
\hline Hemostatic agent 2 & ViscoStat ${ }^{\circledR}$ & $\begin{array}{l}\text { Ultradent do Brasil } \\
\text { produtos odontológicos, } \\
\text { Indaiatuba, SP, Brasil }\end{array}$ & $20 \%$ ferric sulfate $\mathrm{Fe}_{2}\left(\mathrm{SO}_{4}\right)_{3}$ \\
\hline Adhesive resin & $\begin{array}{l}\text { Single Bond Universal } \\
\text { Adhesive }\end{array}$ & \multirow{3}{*}{$\begin{array}{l}\text { (3M Deutschland GmbH } \\
\text { Dental Products Carl- } \\
\text { Schurz-Str. } \quad 1 \quad 41453 \\
\text { Neuss - Germany) }\end{array}$} & $\begin{array}{l}\text { MDP Phosphate Monomer, } \begin{array}{r}\text { Dimethacrylate } \\
\text { resins, HEMA, Vitrebond }\end{array} \text { Copolymer,Filler, } \\
\text { Ethanol,Water,Initiators, Silane }\end{array}$ \\
\hline Resin composite & Filtek $^{\mathrm{TM}} \mathrm{Z} 350 \mathrm{XT}$ & & $\begin{array}{l}\text { bis-GMA,UDMA,TEGDMA, } \\
\text { and bis-EMA(6) resins. PEGDMA. A combination } \\
\text { of non-agglomerated silica filler, non-agglomerated/ } \\
\text { non aggregated zirconia filler, and aggregated } \\
\text { zirconia/silica } \\
\text { cluster filler }\end{array}$ \\
\hline Acid etchant & $\begin{array}{l}\text { Scotchbond }{ }^{\mathrm{TM}} \\
\text { Universal Etchant }\end{array}$ & & $\begin{array}{l}34 \% \text { phosphoric acid by weight, a } \mathrm{pH} \text { of } \\
\text { approximately } 0.1 \text {. Fumed silica and a water-soluble } \\
\text { polymer. }\end{array}$ \\
\hline
\end{tabular}


phosphoric acid (Scotchbond $^{\mathrm{TM}}$ Universal Etchant) to the preparation and left to react for $15 \mathrm{sec}$., rinsed thoroughly with water for 15 sec. and blot dried with cotton pellets without overdrying. Single Bond Universal adhesive was applied using a disposable applicator to the entire prepared tooth structure. It was rubbed in for $20 \mathrm{sec}$. Subsequently, a gentle stream of air is directed over the liquid for about $5 \mathrm{sec}$.until it no longer moves and the solvent has evaporated completely. The adhesive was light cured for 10 sec. using LED light-curing system (Demi LED Light-curing System, Kerr Corp, OA, USA) at intensity of $1000 \mathrm{~mW} / \mathrm{cm} 2$ perpendicular to the surface.

- Group 2 (A1B1): All the procedures were the same as those in group 1 except that before the bonding procedures, Hemostop (Dentsply) was applied for 2 minutes at the cavity margins using a mini-brush, followed by rinsing for 30 seconds and drying with air spray.

- Group 3 (A2B1): All the procedures were the same as those in group 1 except that before the bonding procedures, ViscoStat ${ }^{\circledR}$ (Ultradent) was applied for 2 minutes at the cavity margins using a mini-brush, followed by rinsing for 30 seconds and drying with air spray.

- Group 4 (A0B2): All the procedures were the same as those in group 1 except that self etch adhesive was applied, air dried then light cured according to manufacturer recommendation without prior etching step.

- Group 5 (A1B2): All the procedures were the same as those in group 4 except that before the bonding procedures, Hemostop (Dentsply) was applied for 2 minutes at the cavity margins using a mini-brush, followed by rinsing for 30 seconds and drying with air spray.

- Group 6 (A2B2): All the procedures were the same as those in group 4 except that before the bonding procedures, ViscoStat ${ }^{\circledR}$ (Ultradent) was applied for 2 minutes at margins using a mini-brush, followed by rinsing for 30 seconds and drying with air spray.

A3 shade of Filtek ${ }^{\mathrm{TM}}$ Z350 XT (3M ESPE) was used to restore all cavities using the incremental technique (two 1-mm layers). Each layer was light cured for 20 seconds, following the manufacturer's instructions.

\section{Thermocycling}

After the restorative procedures, to simulate conditions of the oral cavity, all teeth were stored in distilled water for 24 hours at $37{ }^{\circ} \mathrm{C}$ for 24 hours at $100 \%$ humidity. Subsequently, they were exposed to a 1000-cycle thermocycling procedure at $5^{\circ} \mathrm{C} / 55^{\circ} \mathrm{C} \pm 2^{\circ}$ with a dwell time of 30 seconds (THE1100 SD Mechatroniks thermocycler- Germany).

\section{Aging}

All teeth were, thereafter, stored in artificial saliva for 2 years at a temperature of $37^{\circ} \mathrm{C}$ in (Lab Line Imperia II incubator). The artificial saliva was refreshed every one week according to Toodehzaeim and Khanpayeh in 2015. ${ }^{11}$

\section{Microleakage testing}

The apices of the teeth were sealed with wax and the entire surface of each tooth was then covered with two 50 coats of water resistant acrylic finger-nail polish up to a one $\mathrm{mm}$ from the tooth restoration interface. The teeth were then immersed in $2 \%$ methylene blue solution for 24 hours at room temperature. Thereafter, teeth were rinsed thoroughly with tap water for $15 \mathrm{~min}$, dried and invested with the apices downward in clear, fast-cure acrylic resin (Acrostone, Egypt). Each tooth was sectioned in the bucco-lingual direction through the center of the bulk of $\mathrm{Cl} \mathrm{V}$ restorations with slow-speed, water-cooled diamond coated disc (Buehler, Germany). ${ }^{12}$ 
Each section was photographed using USB Digital microscope with a built-in camera (Scope Capture Digital Microscope, Guangdong, China) connected with an IBM compatible personal computer using a fixed magnification of 40X, Fig.1. A digital image analysis system (Image J 1.43U, National Institute of Health, USA) was used to measure and quantitatively evaluate the depth of dye penetration. Within the Image J software, all limits, sizes, frames and measured parameters are expressed in pixels. Therefore, system calibration was done to convert the pixels into absolute real world units. Calibration was made by comparing an object of known size (a ruler in this study) with a scale generated by the Image $\mathrm{J}$ software. Then, the images of traced dye penetration path were overlaid and transferred to Image $\mathbf{J}$ software in order to calculate dye penetration depth in $(\mathrm{mm})$.

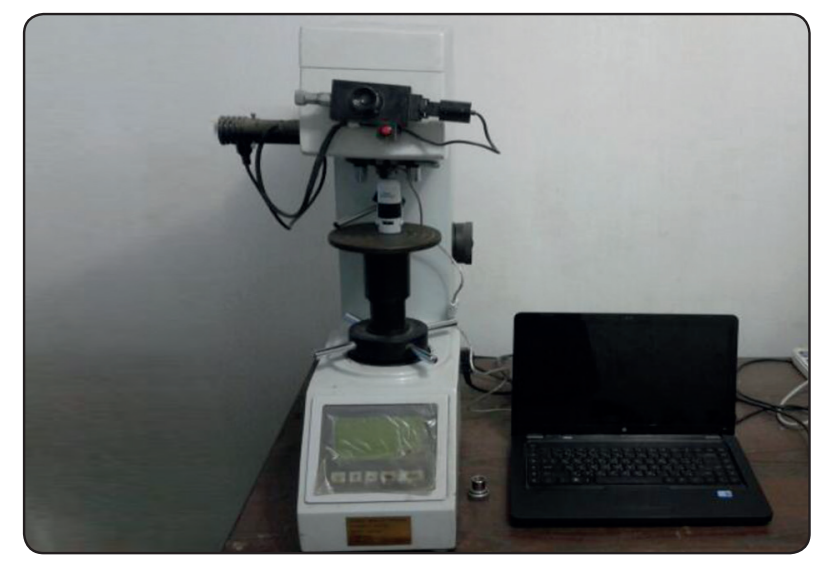

Fig. (1) Digital microscope with a built-in camera

\section{Statistical analysis:}

The normal distribution of data (ShapiroWilk's test) and the homogeneity of the variances (leven's test) were assessed. The two-way ANOVA was performed to highlight the effect of hemostatic agent (A), adhesive protocol (B) and the interaction between both variables $\left(A^{*} \mathrm{~B}\right)$. ANOVA was followed by a post-hoc test (Duncan's test) for multiple comparisons among experimental conditions. Effect size is reported using eta square $\left(\eta^{2}\right)$ index from main and interaction effects. Eta square is defined as the proportion of variance in the dependent variable that is explained by study independent variable (Cohen, 1992) ${ }^{13}$. The results were expressed as the mean \pm standard deviation (SD). Statistical analysis was performed with IBM ${ }^{\circledR}$ SPSS ${ }^{\circledR}$ (SPSS Inc., IBM Corporation, NY, USA) Statistics Version 21 for Windows.

\section{RESULTS}

A two-way unrelated ANOVA showed significant main effect for hemostatic agent, adhesive protocol ( $p=0.0001)$. Regarding the hemostatic agent, it had a large effect size $\eta^{2}=86.5 \%$ which means that 86.5 $\%$ of variance of leakage variable was predictable from the three levels of hemostatic agent when all of the other variables are held constant. While, for the adhesive protocol, the effect size was medium $\eta^{2}=68.6 \%$ which means that $68.5 \%$ of variance of leakage variable was predictable from the two levels of adhesive protocol, when all of the other variables are held constant, table 2 and Fig.2 The Duncan post-hoc test revealed that the first level of hemostatic agent A0 (no hemostatic agent) differed significantly from the second and third level (Hemostop and ViscoStat ${ }^{\circledR}$ ), table 3and Fig.3.

Results also showed a significant effect of the interaction between hemostatic agent and adhesive protocol on leakage, $p=0.0001$, with small effect size $\eta^{2}=34.2 \%$ which means that $34.2 \%$ of variance of leakage variable was predictable from interaction effect between hemostatic agent and adhesive protocol when all of the other variables are held constant. This indicates that the levels of adhesive protocol (etching and non etching) were affected differently by three levels of hemostatic agent (Hemostop, ViscoStat ${ }^{\circledR}$ and non- hemostatic) as shown in table 2 and the interaction graph in Fig.5. The Duncan posthoc test revealed that, there was a significant effect between all combinations of six groups of interactions except interaction between viscosat with preetching adhesive protocol, on one hand and Hemostop with and without pre etching adhesive protocol on the other hand , $\alpha=0.05$, as shown in table (3). 
TABLE (2) Two-way ANOVA results and effect size for the effect of Hemostatic agent, adhesive protocol and interaction between them on micro leakage.

\begin{tabular}{|l|c|c|c|c|c|c|}
\hline Source of Variation & $\mathrm{df}$ & Variance & $\mathrm{F}$ & P-value & Significant & Effect Size \% \\
\hline Hemostatic agent & 2 & 0.98 & 173.62 & 0.0001 & $* * *$ & 86.5 \\
\hline Adhesive protocol & 1 & 0.66 & 118.04 & 0.0001 & $* * *$ & 68.6 \\
\hline Heamostatic * Adhesive protocol & 2 & 0.08 & 14.03 & 0.0001 & $* * *$ & 34.2 \\
\hline Error & 54 & 0.01 & & & & \\
\hline
\end{tabular}

**** Highly significant $(p=0.0001)$

TABLE (3) Means values ( $\mathrm{n}=10$ ) and standard deviation (SD) of the effect of Hemostatic agent, adhesive protocol and Hemostatic agent* adhesive protocol on microleakage in $\mathrm{mm}$

\begin{tabular}{|c|c|c|c|c|c|}
\hline \multicolumn{2}{|c|}{ Hemostatic agent (A) } & \multicolumn{2}{c|}{ Adhesive protocol (B) } & \multicolumn{2}{c|}{ Hemostatic agent*Adhesive protocol } \\
\hline A & Mean \pm SD & B & Mean \pm SD & A*B & Mean \pm SD \\
\hline A0 & $0.26^{\mathrm{a}} \pm 0.12$ & B1 & $0.41^{\mathrm{a}} \pm 0.18$ & A0B1 & $0.15^{\mathrm{a}} \pm 0.03$ \\
\hline A1 & $0.57^{\mathrm{b}} \pm 0.05$ & $\mathrm{~B} 2$ & $0.63^{\mathrm{b}} \pm 0.22$ & A0B2 & $0.38^{\mathrm{b}} \pm 0.02$ \\
\hline A2 & $0.71^{\mathrm{c}} \pm 0.20$ & - & - & A1B1 & $0.53^{\mathrm{c}} \pm 0.02$ \\
\hline- & - & - & - & A1B2 & $0.61^{\mathrm{d}} \pm 0.04$ \\
\hline- & - & - & - & A2B1 & $0.54^{\mathrm{cd}} \pm 0.03$ \\
\hline- & - & - & A2B2 & $0.87^{\mathrm{e}} \pm 0.16$ \\
\hline
\end{tabular}

Means in the same column followed by the same letter are not significantly different based on Duncan test at 0.05 significance level.

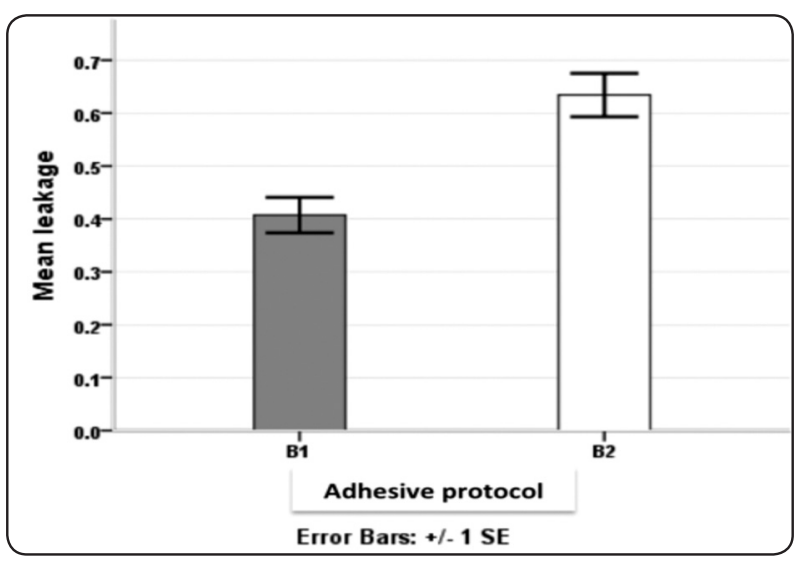

Fig. (2) Bar chart showing the effect of the adhesive protocol on the micro leakage in mm B1:Etching B2:No etching .

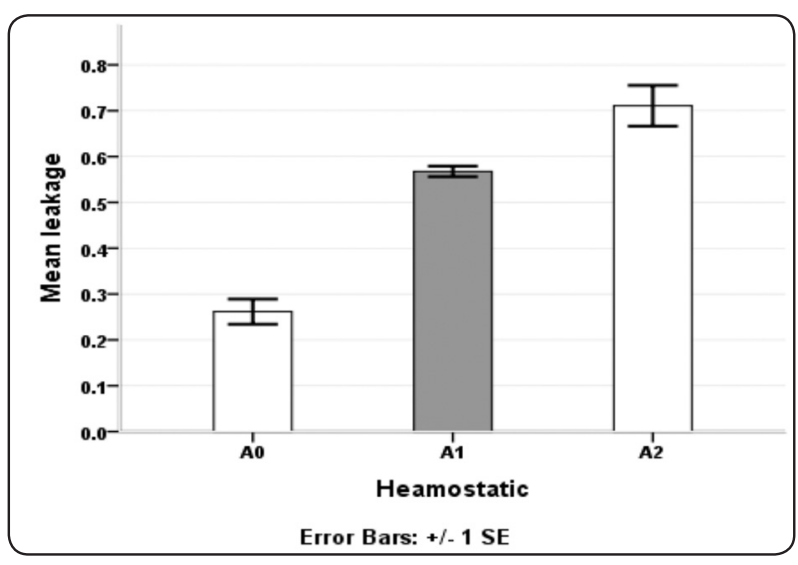

Fig. (3) Bar chart showing the effect of the hemostatic agent on micro leakage in mm A0: No hemostatic agent A1: Hemostop A2:Viscostat 


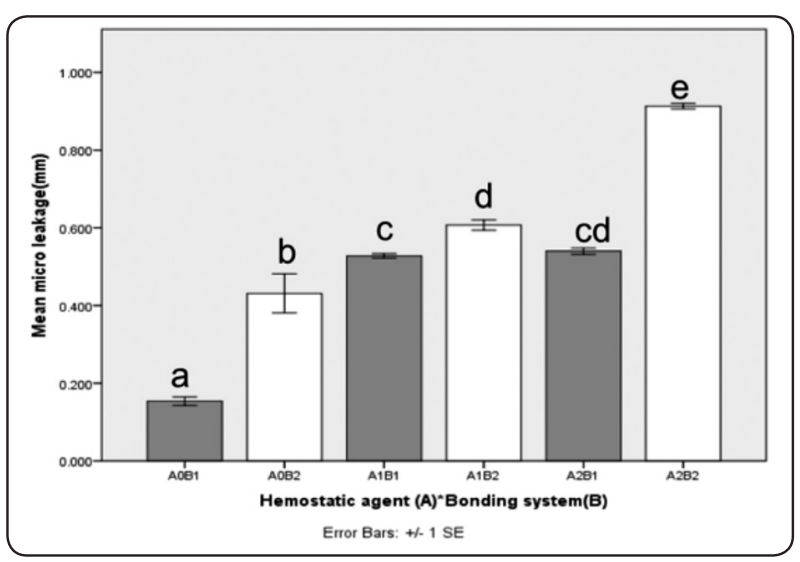

Fig. (4) Bar chart showing the effect of interaction between hemostatic agents and adhesive protocol. Common letters mean insignificant difference at 0.05 level of significance.

\section{DISCUSSION:}

The bond strength between dentin and resin composite restoration is influenced by the quality of the hybrid layer. ${ }^{14}$ To obtain an adequate hybrid layer, a leak proof interface and a longer lasting resin composite restoration should be available. Moreover, contamination of the prepared dentin should be avoided, internal agents such as salivary and gingival fluids and blood or external agents such as the lubricating oil of high speed and hemostatic agents should all be controlled. ${ }^{15}$ Raffaini et al., in 2008 concluded that blood contamination significantly reduces resin/dentin bond strength more than does salivary contamination. ${ }^{16}$

There are several kinds of hemostatic agents, such as aluminum chloride and ferric sulphate with concentrations of $5-25 \%$ have minimal systemic effects, these hemostatic agents are of the most frequently used astringents that can precipitate proteins, constrict blood vessels, and extract fluid from tissues. ${ }^{17} \mathrm{Such}$ hemostatic agents have been evaluated in multiple clinical and in vivo studies for the management of hemorrhage in clinical dentistry. If the use of the hemostatic agents leads to interference with bonding qualities, still constitutes an apprehension.

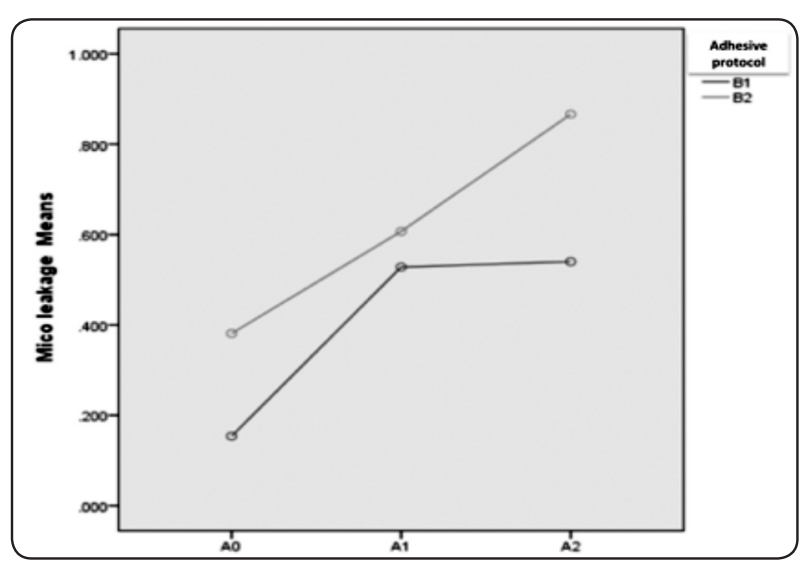

Fig. (5) Graph of the interaction of hemostatic agent and adhesive protocol.

In the current study, two adhesive protocols were used; Self etch adhesives with and without pre-etching step to evaluate the effect of etching. The same adhesive resin, Single Bond Universal was selected for both adhesive protocols to avoid any effect due to the differences of the chemistry of the adhesive materials.

In order to simulate conditions of the oral cavity, the specimens were subjected to a thermocycling procedure, thereafter, they were stored in artificial saliva for two years, which could lead to more precise and practical results.

All the specimens showed some leakage at tooth-restoration interfaces, which might be due to the polymerization shrinkage of the resins, and the differences in the coefficient of thermal expansion and contraction between the teeth and restorative materials. Such changes results in internal stresses in resinous materials, leading to gap formation at tooth-restoration interface and microleakage. ${ }^{18}$

The results of the present study came in line with previous studies that concluded that hemostatic agent (aluminum chloride or ferric sulfate-based) remains cause changes in the dentin surface, harming the bond results. ${ }^{19,20}$ Arslan et al., in 2012 and Sharafeldin et al., in 2015, concluded that 
contamination with a hemostatic agent reduced the shear bond strength of both etch and rinse and self-etching adhesive systems. ${ }^{21}{ }^{22}$ The loss of microtensile bond strength after 2 and 6 years of artificial aging in salivawas reported. It could be due to the remaining amount of hemostatic agents that affects the chemical bond and micromechanical retention of adhesives, resulting in lower bond strengths. ${ }^{17}$ Moreover, it was concluded that the acidity of the hemostatic agents dissolves the smear layer and might obliterate the dentinal tubules and demineralize dentinal surface. Granular precipitates, which remain even after acid-etching, were noted on surfaces exposed to hemostatic agent. The contact of prepared dentin surface with hemostatic agents alters its morphology and reduced the dentin's susceptibility to acid-etching. ${ }^{18}$

Hemostatic agents have acidic properties $(\mathrm{pH}=0.7-3)$ and hydrophilic characteristics that could result in some changes in dentin surfaces which affect the hybrid layer quality after the use of totalor self- etching adhesive systems. ${ }^{8}$ The destruction of the smear layer and demineralization or even removal of the peritubular dentin which results upon using hemostatic agents can create a deeply etched dentin that might be too deep to be penetrated by the limited diffusion of adhesive, especially with the use of a viscous self-etch adhesive. ${ }^{23},{ }^{24}$ Bernades et al. in 2014, concluded that, the bond strength of self-etching adhesive systems could be affected more negatively than that of etch and rinse systems. ${ }^{25}$ Other studies showed that the hemostatic agents have more harmful effect on the marginal seal when self etch adhesives are used compared to etch and rinse adhesives. ${ }^{26-28}$ Phosphoric acid with $\mathrm{pH} \leq 0.5$ in chemical composition of etchand-rinse adhesives might help remove most of the contaminants from the dentin surface before the application of the adhesive resin ${ }^{8}$.

Moreover, the results of this study revealed that sulfate based hemostatic agent (ViscoStat $\left.{ }^{\circledR}\right)$ had higher leakage value than aluminum chloride based hemostatic agent (Hemostop). This comes in accordance to the study conducted by Kumar et al in 2012, who reported that the viscous nature of the ferric sulfate-based hemostatic agent made its removal by acid etching harder. ${ }^{2}$ The composition of the hemostatic agent has been reported to endorse coagulation of proteins present in the dentinal fluid, and this correlates with the ineffective penetration of the adhesive systems, consequently responsible for the bond failure.

On the other hand, our results contradicted those of the previous study conducted by Khoroushi et al. in 2016 who concluded that, the application of different hemostatic agents did not result in statistically significant differences in microleakage of either methacrylate-based or silorane-based resin composites. This conflict could be due to the difference of resin composite used in both studies. ${ }^{29}$

\section{CONCLUSION}

Considering the limitations of this in vitro study, it may be concluded that:-

1. Contamination with hemostatic agents adversely affected the bonding qualities of self etch adhesives applied with and without pre-etching step.

2. Dentin etching prior to self etch adhesives minimized the harmful effect of the hemostatic agents. Thus the null hypothesis was rejected.

\section{RECOMMENDATIONS:}

1. Using of acid etching is highly recommended when hemostatic agents are used

2. Further in vitro and in vivo studies are necessary to improve the understanding of the effect of interactions between different hemostatic agents and different bonding systems. 


\section{REFERENCES}

1 Evancusky JW, and Meiers JC. Microleakage of Compoglass-F and Dyract-AP compomers in Class V preparations after salivary contamination. Pediatr Dent.2000; 22:39-42

2 Kumar P, Shenoy A, and Joshi S. The effect of various surface contaminants on the microleakage of two different generation bonding agents: A stereomicroscopic study. J Conserv Dent. 2012; 15:265-9.

3 Carvalho Mendonca EC, Vieira SN, Kawaguchi FA, Powers J, and Matos AB. Influence of blood contamination on bond strength of a self-etching system. Eur J Dent 2010; 4:280-286.

4 de Oliveira Bernades K, Hilgert LA, Ribeiro AP, Garcia FC, Pereira PN. The influence of hemostatic agents on dentin and enamel surfaces and dental bonding: A systematic review. J Am Dent Assoc 2014;145:1120-1128.)

5 Pardis Tarighi, and Maryam Khoroushi. A review on common chemical hemostatic agents in restorative dentistry. Dent Res Journal 2014; 11: 423-428.

6 Cenci MS, Pereira-Cenci T, Donassollo TA, Sommer L, Strapasson A, and Demarco FF. Influence of thermal stress on marginal integrity of restorative materials. J Appl Oral Sci. 2008;16:106-10.

7 Fathpour K, and Khoroushi M. Effect of trichloroacetic acid hydrogel on self-etch adhesive bond strength to dental tissues. J Contemp Dent Pract. 2013;14:375-80.

8 Thomas MS, Joseph RM, and Parolia A. Nonsurgical gingival displacement in restorative dentistry. Compend Contin Educ Dent 2011;32:26-34.

9 Harnirattisai C, Kuphasuk W, Senawongse P, and Tagami J. Bond strengths of resin cements to astringent-contaminated dentin. Oper Dent. 2009; 34:415-22

10 Ebrahimi SF, Shadman N, and Abrishami A. Effect of ferric sulfate contamination on the bonding effectiveness of etch-and-rinse and self-etch adhesives to superficial dentin. J Conserv Dent. 2013;16:126-30.

11 Toodehzaeim, M. H., and Khanpayeh, E. Effect of Saliva $\mathrm{pH}$ on Shear Bond Strength of Orthodontic Brackets. Journal of Dentistry 2015; 12(4), 257-262.

12 Ajami AA, Kahnamoii MA, Kimyai S, Oskoee SS, Pournaghi-Azar F, and Bahari M. Effect of three different contamination removal methods on bond strength of a self-etching adhesive to dentin contaminated with an alu- minum chloride hemostatic agent. J Contemp Dent Pract. 2013;14:26-33.

13 Cohen, J. (1992). Quantitative methods in psychology: A power primer. Psychological Bulletin, 112(1), 155-159.

14 Nakabayashi N. The hybrid layer: a resin-dentin composite. Proceedings of the Finnish Dental Society 1992;88 Suppl 1:321-329.

15 Chang SW, Cho BH, Lim RY, Kyung SH, Park DS, and Oh TS. Effects of blood contamination on microtensile bond strength to dentin of three self-etch adhesives. Oper Dent. 2010;35:330-6.

16 Raffaini, MS, Gomes-Silva JM, Torres-Mantovani CP, Palma-Dibb RG, and Borsatto MC. Effect of blood contamination on the shear bond strength at resin/dentin interface in primary teeth. Am J Dent. 2008;21:159-62.

17 Gupta G, Kumar S, Rao H, Garg P, Kumar R, and Sharma A. Astringents in dentistry- A review. Asian J Pharm Health Sci. 2012; 2: 428-432.

18 M R, Sajjan GS, and B N K, Mittal N. Effect of different placement techniques on marginal microleakage of deep class-II cavities restored with two composite resin formulations. J Conserv Dent. 2010;13:9-15.

19 Chaiyabutr Y,and JC Kois. The effect of tooth-preparation cleansing protocol on the bond strength of self-adhesive resin cement to dentin contaminated with a hemostatic agent. Oper Dent 2011;36:18-26.

20 Kuphasuk W, Harnirattisai C, Senawongse P, and Tagami J. Bond strengths of two adhesive systems to dentin contaminated with a hemostatic agent. Oper Dent 2007;32:399-405.).

21 Arslan S, Ertaş H, and Zorba YO. Influence of Ankaferd Blood Stopper on shear bond strength of bonding systems. Dent Mater J. 2012; 31: 226-231.

22 Sharafeddin F, and Farhadpour H. Evaluation of Shear Bond Strength of Total- and Self-etching Adhesive Systems after Application of Chlorhexidine to Dentin Contaminated with a Hemostatic Agent. J Dent Shiraz UnivMed Sci. 2015; 16(3): 175-181.

23 Khoroushi M, and Tavasoli M. The effect of trichloracetic acid as a hemostatic and etching agent on the morphological characteristics and shear bond strength of resin composite to enamel.Oper Dent. 2010; 35(2):187-93.

24 Sharafeddin F, Yousefi H, Modiri S, Tondari A, and 
Safaee Jahromi S. Microleakage of Posterior Composite Restorations with Fiber Inserts Using two Adhesives after ging. Journal of Dentistry. 2013;14(3):90-95.

25 Bernades Kde O, Hilgert LA, Ribeiro AP, Garcia FC, and Pereira PN. The influence of hemostatic agents on dentin and enamel surfaces and dental bonding: A systematic review. J Am Dent Assoc. 2014;145:1120-8.

26 Akca EA, Yildirim E, Dalkiz M, Yavuzyilmaz H, and Beydemir B.Effects of different retraction medicaments on gingival tissue. Quintessence Int 2006;37:53-9

27 Kimmes NS, Olson TL, Shaddy RS, and Latta MA. Effect of ViscoStat ${ }^{\circledR}$ and ViscoStat ${ }^{\circledR}$ Plus on composite shear bond strength in the presence and absence of blood. J Adhes Dent 2006;8:363-6.

28 Mohammadi N, Kimyai S, Bahari M, Pournaghi-Azar F, and Mozafari A. Effect of aluminum chloride hemostatic agent on microleakage of class $\mathrm{V}$ composite resin restorations bonded with all-in-one adhesive. Med Oral Patol Oral Cir Bucal 2012;17:e841-4.

29 Khoroushi, M., Shirban, F., and Sahraneshin-Samani, M. Marginal integrity of low-shrinkage and methacrylatebased composite resins: Effect of three different hemostatic agents. J Clin Exp Dent. 2016; 8(2): 78-83. 